\title{
Impact Mechanism and Risk Assessment of Climate Change on Coastal Economic Development
}

\author{
Feng Wang ${ }^{1,2}$ Qiang Long ${ }^{1}$, Xinyue $\mathrm{Mi}^{1}$, Yue $\mathrm{Liu}^{1}$, Ren Zhang ${ }^{3}$ \\ 1.Caofeidian Meteorological Bureau, Hebei Tangshan 063200 \\ 2.Tangshan Meteorological Bureau, Hebei Tangshan 063200
}

3. Meteorological and Oceanographic College, National University of Defense Technology, Jiangsu Nanjing 211101

q_loong@126.com

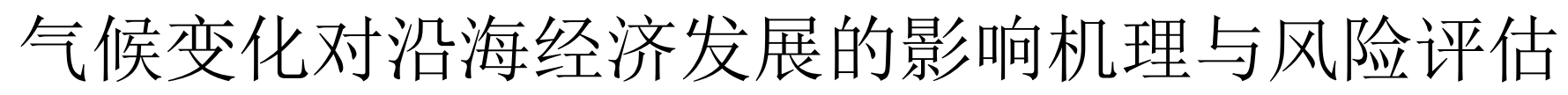

\author{
王锋 ${ }^{1,2}$, 龙强 ${ }^{1}$, 米欣悦 ${ }^{1}$, 刘跃 ${ }^{1}$, 张韧 \\ 1. 唐山市曹妃甸区气象局, 河北 唐山063200 \\ 2. 唐山市气象局, 河北 唐山 063000 \\ 3. 国防科技大学气象海洋学院, 江苏南京 211101 \\ q_1oong@126.com
}

\begin{abstract}
Global climate change characterized by temperature rising has become an indisputable fact, which has become a common problem and a major challenge of the whole world today. Coastal areas are the most significant, most responsive, and most uncertain and diverse regions affected by global climate change. According to the climate change impact and disaster risk faced by China's coastal economic development, the impact mechanism of climate change on coastal economic development is analyzed. The disaster chain method is used to deduct the structure of the disaster chain system that may be faced in coastal areas, and the conceptual model of climate change risk is constructed. A risk assessment indicator system based on typical disasters in coastal areas such as tropical cyclones, sea level rise and storm surges was established. The application demonstration of tropical cyclone risk assessment for climate change scenarios and experimental zoning was carried out, In order to provide reference and reference for China's coastal economic development to cope with climate change and prevent climate risks.
\end{abstract}

Keywords-Climate change, coastal areas, economic development, disaster risk, assessment system

摘要一以气温上升为主要特征的全球气候变化已成为不 争的事实, 成为当今世界面临的共同问题和重大挑战。沿海地 区是受全球气候变化影响最显著、响应最敏感和最具不确定 性、多样化的地区。针对我国沿海经济发展面临的气候变化影 响和灾害风险, 分析了气候变化对沿海经济发展的影响机理, 并采用灾害链法演绎推导了沿海地区可能面临的灾害链系统 结构, 构建了气候变化风险概念模型, 以及基于热带气旋、海 平面上升和风暴潮等沿海地区典型灾害的风险评价指标体系, 开展了气候变化情景的热带气旋风险评估与实验区划的应用 示范, 以期为我国沿海地区经济发展应对气候变化、防范气候 风险提供借鉴和参考。 评估体系

关键词一气候变化；沿海区域；经济发展；灾害风险；

I. 全球气候变化与沿海区域响应

中国拥有大陆海岸线 1.8 万多平方千米, 沿海地区共 有 14 个省级行政区，自北向南依次为: 辽宁省、河北省、 天津市、山东省、江苏省、上海市、浙江省、福建省、广 东省、广西壮族自治区、海南省以及台湾省、香港特别行
政区和澳门特别行政区。沿海地区占全国 13.6\%的国土面 积，承载了全国近 $41 \%$ 的人口，涵盖了全国 $70 \%$ 以上的 大城市，创造了全国 $60 \%$ 以上的 GDP，是人口稠密、城 市集中，经济发达的地区。

我国濒临西北太平洋和黄海、东海、南海, 海洋环境 复杂多变, 沿海地区又处于海洋与大陆交汇地带, 是海 洋灾害袭击的前沿。因此, 中国沿海地区一向是我国海 洋灾害频繁发生和受灾严重的地带。同时, 也是世界海 洋灾害最严重地带之一（左书华,李蓓,2008)。近十年来, 随着全球气候的变化, 海洋灾害的发生呈现出了增多的 趋势（许小峰,顾建峰等,2009）。气候变化使原本就灾害 频发的沿海地带面临更多、更大的灾害威胁风险。

海平面上升和随之衍生的海岸带侵蚀是气候变化最 直接的后果之一。据相关文献 (季子修,1996; 季荣耀, 罗章仁,2009; 2007 中国海平面公报等) 报告, 近 40 年 来, 渤海沿岸约 $400 \mathrm{~km}^{2}$ 的耕地、盐场和村庄被海水淹没; 广东省水东沿岸临海的上大海渔村, 近百年来因海岸侵 袭而向内陆迁村 3 次, 侵蚀速率达 1.5-2.0 m/a; 海南乐东 县龙栖湾村附近海岸 11 年内后退了 200 余米, 数十间房 屋被毁，村庄 3 次搬迁，村民生存空间越来越小。

另外, 全球气候变暖不仅可引发海平面上升, 而且也 会导致热带气旋、风暴潮等海洋灾害的强度和频率发生 变异, 呈现出逐渐增加的趋势。根据国家海洋局 1989-2009 年《中国海洋灾害公报》中提供的数据, 近 21 年来, 中国沿海地区遭受的海洋灾害损失巨大，直接经 济损失累计达 2620 亿元, 几乎有一半年份受到的经济损 失超过 100 亿元。图 1 反映近 21 年来我国沿海地区台风 风暴潮灾害发生情况, 图 2 为近 13 年来我国风暴潮灾害 损失情况。可以看出近年来我国台风风暴潮灾害发生频 次有所增加, 造成的经济损失占据了海洋灾害总损失的 绝大部分比例。风暴潮灾害不仅居海洋灾害之首, 而且 随着全球气候的持续变暖, 风暴潮灾害已经成为威胁我 国沿岸经济发展最严重的灾害之一。 
表 1 沿海经济发展风险评价指标体系

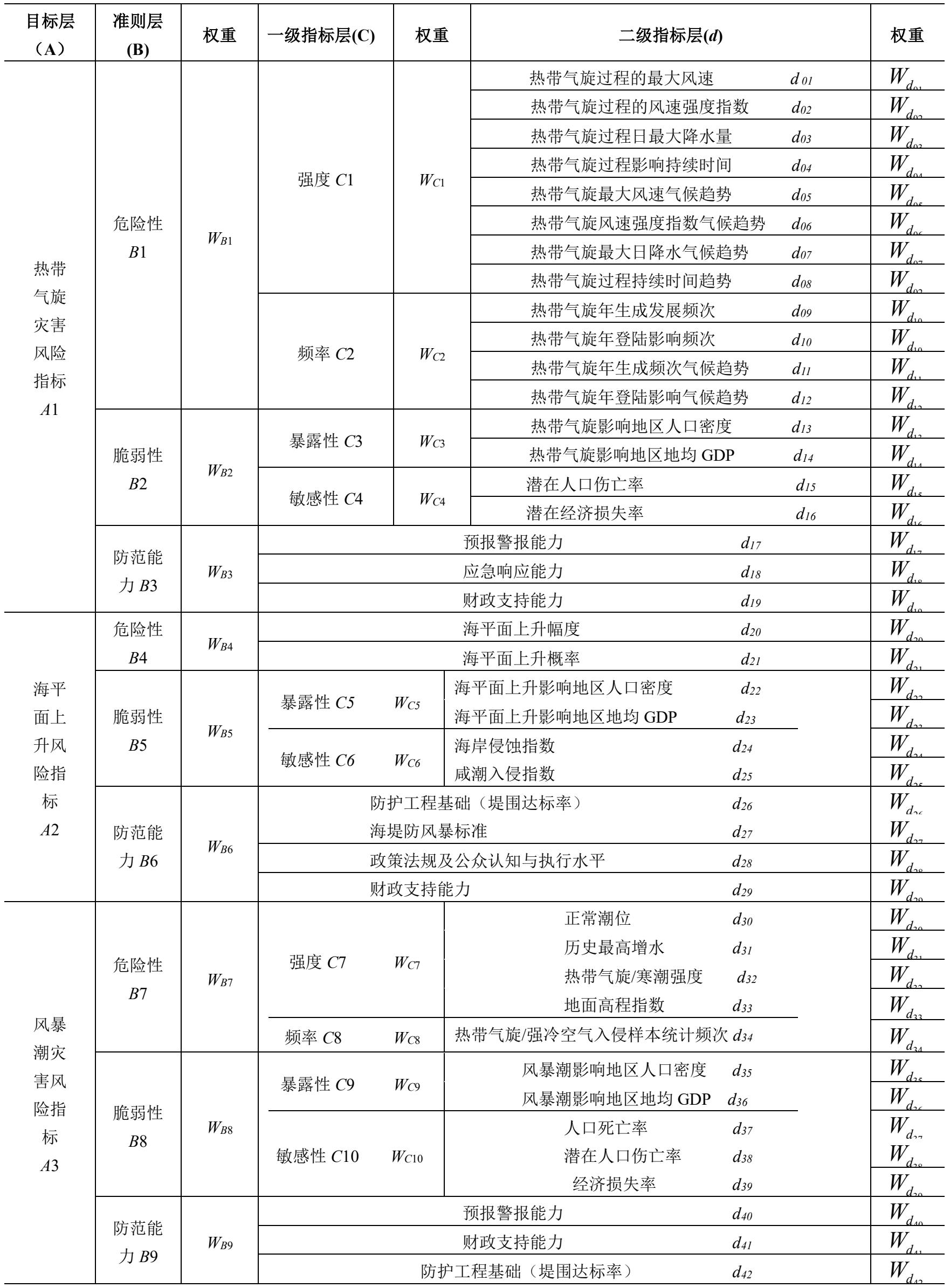




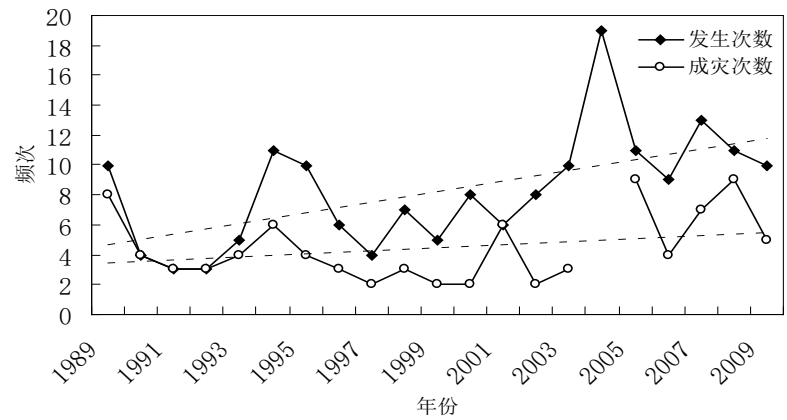

图 1 1989-2009 年我国台风暴潮频数序列

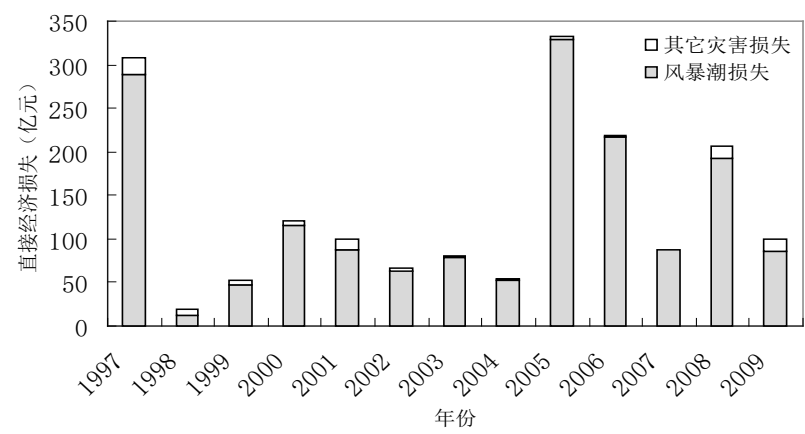

图 2 1993-2009 年我国海洋灾害损失情况

（数据来源：国家海洋局 1989-2009 年《中国海洋灾害公报》)

\section{II. 气候变化与沿海地区灾害链}

气候变化对沿海经济发展的影响, 主要表现为气候变 化导致沿海地区的海洋灾害加剧, 造成经济发展成本上
升、收益减少。首先, 灾害问题的加剧, 迫使国家或地 方政府不得不加大减灾力度, 增加防灾减灾投入, 造成 经济发展的成本不断上升; 其次, 一定时期内的社会财 富是固定的, 防灾减灾的投入扩大, 用于直接经济发展 的投入必然减少, 社会再生产的发展无疑受到制约; 再 者, 重大灾害发生或者一般灾害的频繁发生, 都会使已 经积累的社会财富遭受一定数额的损失, 正常的社会生 产中断, 灾后重建也会导致一段时期内社会发展的停滞。 简单来说, 灾害的增加将导致经济收益的减少, 使经济 发展速度减缓, 给沿海地区经济的持续发展带来消极影 响。因此, 可以从气候变化使沿海地区面临的海洋灾害 危险程度及损失大小的角度, 来评估气候变化对沿海经 济发展造成的损失风险。基于此, 可将 “沿海经济发展 风险” 定义为: 气候变化致使沿海地区遭受海洋灾害威 胁、造成人民生命财产损失, 影响经济发展的可能性/几 率及其灾害损失程度。

全球气候变化背景下, 多种灾害的共同作用, 使沿海 地区既受到直接灾害影响、也面临一系列次生灾害的威 胁, 影响过程和灾害链: 海平面上升直接导致潮位升高, 风暴潮致灾程度增强, 海水入侵面积和范围加大, 洪涝 灾害加剧; 潮差和波高的增大, 将减弱沿岸防护堤坝能 力, 海岸和低地受海水侵蚀程度相应加重; 海平面上升 和淡水资源短缺将使滨海淡水受到污染、农田盐碱化、 河口区咸潮入侵, 进而增加排污难度、破坏生态平衡。 为梳理上述各灾害之间的层次结构与逻辑关系, 采用灾 害链法由因及果演绎推导气候变化背景下沿海地区可能 面临的灾害链系统结构（图 3）。

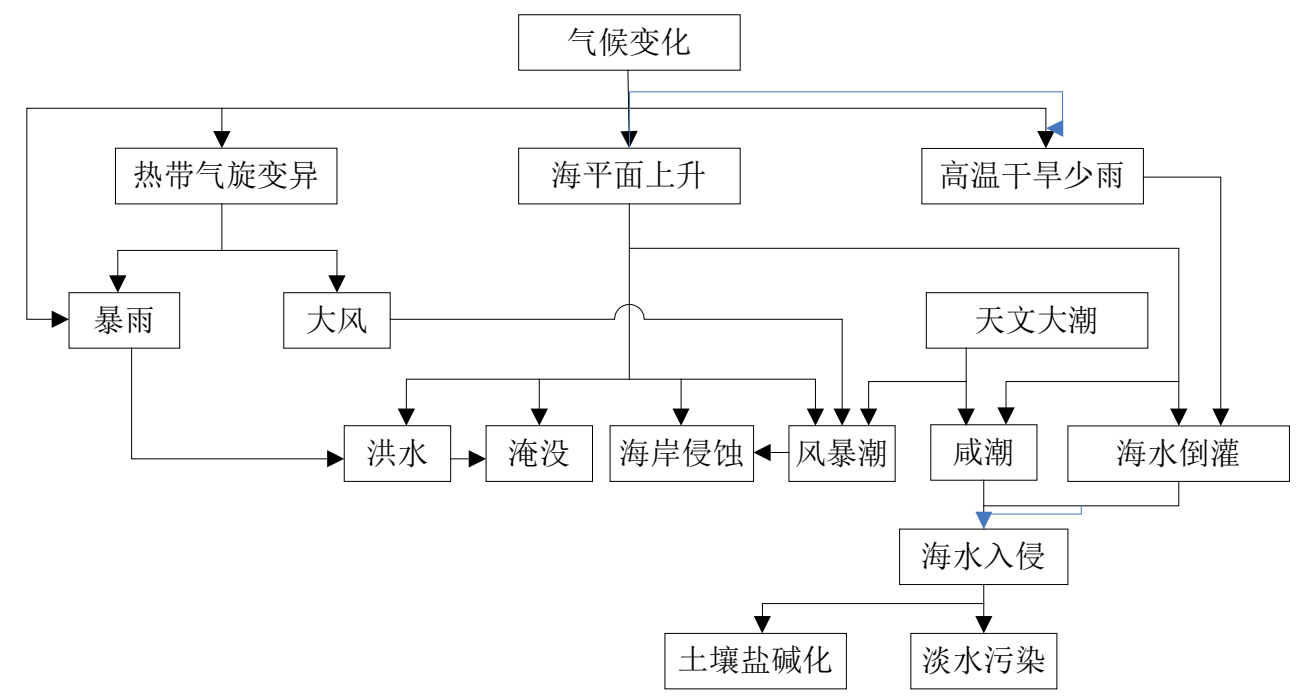

图 3 气候变化背景下沿海地区灾害链

图 3 中可见, 热带气旋变异和海平面上升是气候变化 直接后果, 也是多种次生灾害源头。风暴潮因其危害巨 大, 近些年倍受关注。为此, 选取热带气旋、海平面上 升和风暴潮作为沿海地区典型灾害, 构建气候变化影响 沿海经济发展风险评价指标体系。

\section{III. 风险评价指标体系}

综上气候变化对沿海经济发展的影响因子与影响机 理分析, 可以构建出沿海经济发展的风险评价指标体系

（表 1）。表 1 中，热带气旋灾害是全球发生频率最高、 影响最严重的一种灾害。在全球热带气旋的活动区中, 西北太平洋海区的热带气旋发生频率最高, 约占全球总
数 $36 \%$, 同时西北太平洋中的热带气旋强度也是全球最 强的。中国位于西北太平洋沿岸, 是世界上少数几个遭 受热带气旋影响最严重的国家之一, 南起两广、北至辽 宁的漫长沿海地带经常遭受热带气旋袭击。随着大量热 带气旋历史资料的积累和发布 (如中国气象局上海台风 研究所整编 “CMA-STI 热带气旋最佳路径数据集”、《热 带气旋年鉴》等），为热带气旋风险评估提供了可能。

基于风险评估示范, 本文以省为基本评估单元, 建立 了我国沿海地区 12 个省级行政区 (为便于分析和可视化 表达, 香港、澳门归入广东省地理区域) 热带气旋灾害 风险示范指标体系。 
IV. 沿海地区热带气旋风险实验区划

\section{A. 热带气旋风险评价指标}

热带气旋危险性表示未来一段时间内评估区域可能 遭遇热带气旋影响的危险性, 包括热带气旋强度和影响 频率等特征。基于历史资料的概率统计方法能够较为客 观地反映评估区域的未来状况。因此, 可以在历史数据 资料基础上构建相应的危险性指标。基于不同资料，可 以定义不同的危险性指标体系。分别定义基于《热带气 旋年鉴》和 《CMA-STI 热带气旋最佳路径数据集》的危 险性指标和脆弱性指标体系。

1. 热带气旋危险性指标:

1）热带气旋强度指标；2）热带气旋频率指标.

2. 沿海地区脆弱性指标:

1）承险体暴露性指标；2）承险体敏感性指标。

3. 风险防范能力指标:

1）预警能力指标；2）应急能力指标；3）财政能力。

\section{B. 热带气旋风险实验区划}

基于中国气象局上海台风研究所整编的 1949-2009年 的 CMA-STI 热带气旋最佳路径数据集, 选取我国周边海 域 $\left(95^{\circ} \mathrm{E} \sim 140{ }^{\circ} \mathrm{E}, 0{ }^{\circ} \mathrm{N} \sim 45^{\circ} \mathrm{N}\right)$ 作为研究区域, 按照 GB/T 19201-2006 的热带气旋等级国家标准, 将热带气旋 （简称 $\mathrm{TC}$ ）分为热带低压（TD）、热带风暴（TS）、 强热带风暴（STS）、台风（TY）、强台风 ( STY )、 超强台风 (SuperTY) 进行讨论。采用灾害风险评价指数 方法, 热带气旋灾害风险是其危险性 $(\mathrm{H})$ 、脆弱性 $(\mathrm{V})$ 、 区域防灾减灾能力（R）综合效应结果，可表达为:

\section{$\mathrm{TC}$ 灾害风险指数}

$=$ 危险性 $(\mathrm{H}) \times$ 脆弱性 $(\mathrm{V}) \times(1-$ 区域防灾减灾能力 $(\mathrm{R}))$

建立专家和学者分析和评价小组, 采用层次分析 法 (AHP) 并结合 Delphi 法进行指标体系建立和指标 权重计算; 利用 GIS 空间分析和自然断裂的标准分类 方法展示风险分布, 等值线图 (即色斑图) 绘制采用 Kriging 插值算法。将 TC 危险性分为 5 级, 分别评估 和绘制出我国周边海域热带气旋危险性（图 4a）、脆 弱性 (图 4b) 和风险防范能力 (图 4c) 以及综合风险 区划（图 4d）评估结果。
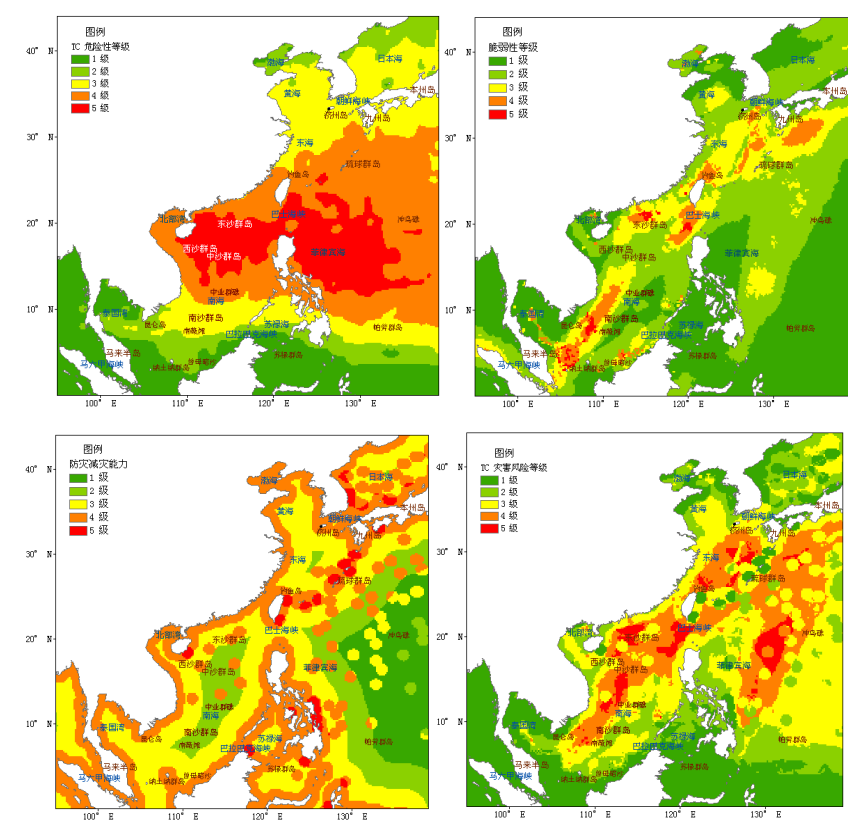

图 4 我国周边海域 TC 危险性(a)、承灾体脆弱性(b)、风险防范能力(c)、 $\mathrm{TC}$ 灾害风险(d)区划

\section{V. 小结}

分析了全球气候变化与我国沿海区域响应特性、气候 灾害机理与灾害链, 构建了气候变化影响沿海经济发展 的风险概念模型和风险评价指标体系, 并以气候变化背 景下热带气旋演变趋势与灾害风险, 探讨了我国周边海 域热带气旋强度及频数的气候变化特征, 基于构建的风 险评价指标体系和评估模型, 应用 GIS 技术开展了我国 周边海域热带气旋灾害风险的评估示范和实验区划。旨 在为我国沿海地区经济发展应对气候变化、防范气候风 险提供借鉴和参考。

\section{参考文献}

[1] 国家海洋局. 2007 年中国海平面公报 .http://www. soa.gov.cn/hyjww/hygb/zghpmgb/2008/01/1200912279807713.htm

[2] 国家海洋局.中国海洋灾害公报. http://www.soa.gov.cn /soa/hygbml/A0110index_1.htm

[3] 季荣耀,罗章仁. “广东省海岸侵蚀特征及主因分析, ”第十四届中国 海洋/岸工程学术讨论会论文集,海洋出版社, 2009.

[4] 季子修. “中国海岸侵蚀特点及侵蚀加剧原因分析, 自然灾害学 报,vol.5, issue 2,pp.65-68, 1996.

[5] 许小峰,顾建峰,李永平.海洋气象灾害. 北京:气象出版社,2009.

[6] 许小峰, 王守荣, 任国玉.气候变化应对战略研究. 北京:气象出版 社,2006.

[7] 中国知网: 中国统计年鉴数据库. http://tongji.cnki.net/ kns55/index.aspx.

[8] 左书华,李蓓. “近 20 年中国海洋灾害特征、危害及防治对策, ”气象 与减灾研究, issue 4, pp.28-33, 2008. 